\title{
Configurações
}

Revista de sociologia

\section{As políticas de modernização e desenvolvimento na Amazónia brasileira: olhares sobre o discurso e a questão ambiental contemporânea}

The politics of modernization and development in the Brazilian Amazon:

Perspectives on discourse and contemporary environmental issues

La politique de modernisation et de développement en Amazonie brésilienne:

Perspectives sur le discours et les enjeux environnementaux contemporains

Pedro Rapozo e Manuel Carlos Silva

\section{OpenEdition}

Edição electrónica

URL: http://journals.openedition.org/configuracoes/1909

DOI: $10.4000 /$ configuracoes. 1909

ISSN: 2182-7419

\section{Editora}

Centro de Investigação em Ciências Sociais

Edição impressa

Data de publição: 1 Junho 2013

Paginação: $67-76$

ISBN: 1646-5075

ISSN: 1646-5075

\section{Refêrencia eletrónica}

Pedro Rapozo e Manuel Carlos Silva, « As políticas de modernização e desenvolvimento na Amazónia brasileira: olhares sobre o discurso e a questão ambiental contemporânea », Configurações [Online], 11 | 2013, posto online no dia 22 setembro 2014, consultado o 30 abril 2019. URL : http:// journals.openedition.org/configuracoes/1909; DOI : 10.4000/configuracoes.1909 


\section{As políticas de modernização e desenvolvimento na Amazónia brasileira: olhares sobre o discurso e a questão ambiental contemporânea}

The politics of modernization and development in the Brazilian Amazon:

Perspectives on discourse and contemporary environmental issues

La politique de modernisation et de développement en Amazonie brésilienne:

Perspectives sur le discours et les enjeux environnementaux contemporains

Pedro Rapozo e Manuel Carlos Silva

\section{Introdução}

1 Neste artigo pretendemos introduzir um diálogo acerca da formação do Estado brasileiro face às políticas de modernização ${ }^{1}$ e desenvolvimento, considerando a sua estrutura jurídico-administrativa no decorrer do século XX. Neste sentido apresentamos como motivo de reflexão o modo como ocorreram as ações através da política de consolidação nacional dos projetos de valorização econômica na região amazónica, no norte do Brasil, delineando como estes elementos se traduziram, contraditoriamente, a partir das transformações socioeconômicas do modo de produção vigente e das formas de uso e apropriação dos recursos naturais.

2 Estas transformações são pensadas sob a perspetiva da dinâmica das relações de trabalho instituídas, reforçadas pelos modelos de desenvolvimento adotados, intensificando assim a exploração dos recursos mediante a inserção dos grandes projetos de valorização econômica. Na medida em que estavam latentes as problemáticas de apropriação/ exploração dos recursos naturais, sobretudo ao longo dos anos 80 e 90, o Estado viu-se situado perante contradições sociais causadas pelo projeto de modernidade acreditado considerando a ineficiência de sua tecnoestrutura jurídico-administrativa -, o que 
possibilitou o surgimento de espaços de discussão sobre os caminhos adotados pelo desenvolvimento e sua preocupação com as questões ambientais.

Neste texto, começando com uma discussão sobre as teorias do desenvolvimento e seus respetivos contributos, produzimos uma reflexão sobre as consequências de uma perspetiva de planeamento económico, o qual, de facto, viria a possibilitar, ainda que tardiamente, uma preocupação com as questões ambientais, dadas as contradições sociais inerentes aos modelos de desenvolvimento adotados no país e nas suas regiões específicas ao longo do último século.

\section{Desenvolvimento, modernização e a emergência da questão ambiental: breve revisitação e confronto teórico}

4 O tema do desenvolvimento nas ciências sociais contemporâneas demarca um campo do pensamento sociológico, do qual decorrem propostas e proposições político-ideológicas no âmbito dos Estados nacionais, em que o conceito de desenvolvimento é, como referem Silva e Cardoso (2005), polissémico. Com efeito, dentre os temas abordados, o conceito de desenvolvimento não tem o mesmo conteúdo e sentido nas várias abordagens ao desenvolvimento.

Dentre as teorias ou correntes do pensamento económico consideradas neste processo, destacam-se importantes debates entre os respetivos defensores das mesmas, tornando-se algumas delas hegemónicas, nomeadamente a (neo)liberal, na condução das políticas económicas. Assim, no campo analítico destacam-se inicialmente as teorias do crescimento e modernização ${ }^{2}$ a partir da década de 50 do século XX e a correlativa proposta do crescimento por etapas, evidenciando o discurso de que os países ditos subdesenvolvidos deverão assumir os pressupostos liberais e perseguir os padrões económicos de modernização, assim como as normas e valores vigentes nos países ocidentais, nomeadamente os mais desenvolvidos. Com efeito, o conceito de modernização tem sido avançado no quadro da teoria liberal sobre o crescimento, cujo principal obreiro foi Rostow (1960), para a qual contribuíram todavia autores de diversas áreas, entre as quais a teoria difusionista na antropologia e a teoria estruturo-funcional de Parsons $(1964,1988)$ e Hoselitz (1982).

6 A modernização foi considerada também a partir de outras abordagens, sendo de referir o próprio Habermas (1990), para quem a modernização é vista como um feixe de processos cumulativos que se reforçam mutuamente "através da formação de capital e mobilização de recursos, ao desenvolvimento de forças produtivas e ao aumento da produtividade do trabalho, ao estabelecimento de poderes políticos centralizados e à formação de identidades nacionais, à expansão de direito de participação política, de formas urbanas de vida, à formação escolar formal e à secularização de valores e normas" (Habermas 1990: 14). Mas o autor que melhor desconstruiu as teorias da modernização (neo)liberal foi Frank (1961), o qual rebate e contesta os axiomas (neo)liberais do crescimento por etapas defendido por Rostow (1960) e, em particular, os pressupostos da perspetiva estrutural-funcionalista no campo da sociologia (cf. Parsons 1988 e Hoselitz 1982). Estes autores, segundo Frank (1961), partem do pressuposto unilinear e teleológico de que, enquanto as sociedades tradicionais estão imbuídas de traços de adscrição em base parental ou compadrio, de particularismo e de difusidade de papéis, as sociedades 
modernas são glorificadas na medida em se caracterizam pela realização na base do mérito próprio, pelo universalismo nas instituições e pela especificidade de papéis, estando pressuposto que as sociedades caminham de modo faseado do tradicional subdesenvolvido para o moderno desenvolvido, sem qualquer referência às contradições do modo de produção capitalista e imperialista.

Uma das reações críticas à escola de pensamento liberal adveio de autores de vários países sobretudo do Norte da Europa, nomeadamente Myrdal (1974), que, perante o impasse e a não resolução do fosso entre países ricos e países pobres, avançou com o que mais tarde seria designado como escola neoinstitucional na medida em que o Estado teria um papel preponderante no arranque e na planificação indicativa para o desenvolvimento.

Ainda que inspiradas na abordagem marxista, nos anos sessenta ganham igualmente destaque as teorias neomarxistas do desenvolvimento e as contribuições para a dimensão do valor do trabalho, bem como a importância da transição dos sistemas e modos de produção, designadamente do feudalismo para o capitalismo e deste para o socialismo. Esta terceira visão sobre a questão do desenvolvimento permitiria uma compreensão mais ampla e uma explicação crítica do subdesenvolvimento enquanto elemento central do próprio funcionamento e desenvolvimento do sistema capitalista. Outros, radicalizando a perspetiva institucionalista, foram desenvolvendo as teorias da dependência ${ }^{3}$ e proporcionaram uma perspetiva alternativa de carácter histórico-estrutural para a explicação dos problemas do subdesenvolvimento através de uma profunda crítica à economia clássica e seus pressupostos.

9 A partir desta perspetiva, o desenvolvimento é repensado de forma diferente, conforme apontam Silva e Cardoso (2005), entre as correntes neomarxistas, as quais se poderiam diferenciar em três variantes teóricas: por um lado, a visão da relação de dependência das regiões e países-satélite face à metrópole, enquanto fator estruturante das desigualdades a nível mundial, tal como afirmaria a teoria da dependência de Frank (1967); por outro lado, a relação entre as economias centrais e periféricas seria marcada por uma compreensão crítica dos modelos de desenvolvimento e suas mudanças estruturais em consonância com a perspetiva do sistema-mundo capitalista de Wallerstein (1990); e, por fim, a defesa de uma teoria da desconexão dos países periféricos como meios para a construção de um novo sistema económico policêntrico (Amin 1974).

Perante a falência das propostas neoliberais, a ineficiência das propostas neoinstitucionais e a utopia considerada irrealizável do socialismo conforme as teorias da dependência e do centro-periferia, outros autores (Stohr, 1981; Reis, 1994; Bailly 1999) avançaram uma outra abordagem, de carácter territorialista e centrada no desenvolvimento endógeno das potencialidades e recursos locais.

11 O desenvolvimento das forças produtivas e correlativas modificações económicas no âmbito da industrialização comportaram também uma reformulação político-ideológica em torno dos ideais de progresso e de desenvolvimento. De modo geral, o surgimento de um debate mais acentuado sobre as problemáticas do desenvolvimento, especialmente na segunda metade do século $\mathrm{XX}$, é caracterizado pelos aspetos históricos das transformações socioeconômicas decorrentes do pós-guerra, consubstanciadas em dois grandes blocos económicos então presentes, particularmente após a Segunda Guerra Mundial no período da Guerra Fria: um capitalista e um outro de planificação socialista (Hidalgo Capitán, 1998). Enquanto as teorias económicas dominantes dos países do chamado primeiro mundo desenvolvido têm associado os debates em torno das políticas de crescimento e de estabilidade do sistema económico vigente e suas estratégias de 
difusão para economias e sociedades não desenvolvidas e as teorias neoinstitucionais procuram superar os impasses e efeitos perniciosos da doutrina neoliberal e os círculos viciosos de subdesenvolvimento, as teorias (neo)marxistas da dependência e do centroperiferia visam inverter o rumo das politicas neoliberais, realimentando e/ou reforçando experiências de planificação socialista.

À teoria e à retórica do discurso de modernização económica defendidas por neoliberais e referidos autores estruturo-funcionais, contrapunham-se análises críticas sobre os processos de dependência em formações económicas periféricas presentes em países latino-americanos como o Brasil, as quais, segundo a abordagem de Marini (2000), permaneceriam, no mercado mundial, subordinadas aos centros do capitalismo e não chegariam aos padrões económicos de modernização almejados. Por conseguinte, estas economias não teriam como constituir de forma consolidada seus mercados internos, perpetuando assim um modelo colonial de desenvolvimento dependente que marcaria toda a submissão política e económica neocolonial por parte do centro sobre as periferias.

Considerando estes aspetos, a América Latina ingressaria na etapa da industrialização a partir das bases criadas pela economia de exportação, ao mesmo tempo que aprofundaria a contradição própria de seu ciclo do capital e seus efeitos sobre a exploração do trabalho. O resultado disso seria o não desenvolvimento de bases tecnológicas e, por consequência, o não surgimento das indústrias mais produtivas e também a necessidade da manutenção da sobre-exploração do trabalho, nos seus mais diversificados aspetos e formas de organização, sem contar com os fatores ambientais resultantes da exploração indiscriminada dos recursos naturais (Correa e Cardeal, 2005).

0 surgimento de correntes e teorias alternativas às teorias liberais acerca do crescimento e do desenvolvimento (Hidalgo Capitán, 1998) possibilitou um debate mais ampliado acerca dos problemas evidenciados no regime de produção capitalista, principalmente com a discussão sobre o esgotamento dos recursos naturais, marcado pela crise (económica) do petróleo na década de setenta do século passado (Leff, 2000). Foi na sequência desta crise que se assistiu ao reforço do neoliberalismo, sobretudo nos anos de reforma económica da década de oitenta, o qual protagonizaria os debates, criticando o modelo keynesiano de intervenção estatal/governamental das décadas anteriores. Por outro lado, as críticas ao modelo de produção dominante e suas irracionalidades foram evidenciando a incongruência teórica e prática do modelo de crescimento (neo)liberal, o qual visa(va) a utilização predadora dos recursos naturais e a instrumentalização das tecnologias ao serviço das lógicas mercantis e dos interesses das grandes corporações.

Dentre os referidos modelos de desenvolvimento alternativos, as temáticas emergentes do ecodesenvolvimento (Sachs, 1993) e do desenvolvimento sustentável, local e territorial, ganhariam maior centralidade, sobretudo quando associadas aos temas da gestão e maior participação da sociedade em geral, e de determinadas populações ou de territorialidades sociais quanto ao acesso, manejo e utilização dos recursos naturais em bases sustentáveis.

16 Assim, a centralidade da questão ambiental apareceria recorrentemente como problema das próprias bases de produção na desconstrução do paradigma económico vigente, estabelecendo limites à construção de novos paradigmas que se direcionassem para a internalização dos fatores ambientais nas questões económicas articuladas ao processo produtivo, o que de facto se materializaria em alguns trabalhos teóricos de relevância e nas conferências que debateriam sobre o tema da questão ambiental a partir da década de 60. 
17 Em termos históricos poderíamos sublinhar os ensaios de Rachel Carson (The Silent Spring, 1962) e de Garrett Hardin (The Tragedy of the Commons, 1968) sobre as preocupações e catástrofes causadas pelo uso desenfreado dos recursos naturais e, posteriormente, o trabalho elaborado sob coordenação de Meadows (1972) com uma abordagem crítica sobre o crescimento económico, seus limites e consequências.

18 No que diz respeito a conferências e cimeiras, podemos destacar a Conferência realizada pela UNEP (1974) no México com a Declaración de Cocoyoc, sendo de salientar a discussão sobre o ecodesenvolvimento a partir das reformulações teóricas propostas por Sachs (1973), prosseguindo o debate iniciado por Strong (1973); o Relatório Dag Hammarskjold (1975) realizado na Alemanha na reunião das Nações Unidas sobre a gestão dos recursos naturais, demonstrando as possibilidades e os ideais de conservação ambiental.

19 Já em 1984 é formada a Comissão Mundial sobre Meio Ambiente e Desenvolvimento na qual, perante os debates antecedentes, é de relevar a elaboração de propostas de avaliação dos processos de degradação ambiental e eficácia na construção de políticas ambientais. Resultado deste debate é o surgimento do Relatório Bruntland (1987) publicado pelas Nações Unidas, conhecido como Our Common Future, o qual apresentaria a proposta conceitual da temática do desenvolvimento sustentável, potencializando a satisfação das necessidades da população sem comprometer a capacidade de atender às gerações futuras.

20 Em 1992 aconteceria a ECO 92, no Rio de Janeiro - Brasil, Conferência das Nações Unidas sobre Meio Ambiente e Desenvolvimento, a qual abordou dentro dos potenciais debates a vinculação da Agenda 21 como um programa global para orientação de uma transição para o desenvolvimento sustentável, buscando discutir os problemas ambientais e os modelos de desenvolvimento, as parcerias para desenvolvimento local sustentável, além de, atendendo à diversidade nos países, potenciar uma avaliação da necessidade de apoio externo e redução dos desperdícios. Estas intervenções tornaram-se cada vez mais frequentes a partir de meados dos anos 90, sendo discutidas contemporaneamente em cimeiras questões como as mudanças climáticas e as políticas de contenção quanto à emissão de poluentes na atmosfera, as quais ganharam cada vez maior visibilidade mundial no campo das políticas e acordos internacionais.

21 Contudo, a discussão e os conceitos emergentes na década de 70, e que se popularizaram no início dos anos 80 através dos eventos e relatórios para a conservação/gestão dos recursos naturais, acabaram transparecendo como um discurso ecológico oficial e não oficial mas sem consenso algum quanto ao seu significado. Ou seja, tal discurso não viria a refletir sobre as possibilidades questionáveis, nem as propostas apresentadas possuiriam algum sentido no quadro de organização institucional e económica do capitalismo, sobretudo nos países desenvolvidos hegemónicos (Rapozo e Witkoski, 2008).

o facto de a degradação socioambiental, gerada pela (ir)racionalidade econômica e tecnológica dominante (Leff, 2000) nos projetos de desenvolvimento, ocupar um lugar central na contemporaneidade não signifi ca dizer que se constituiu, ao longo do tempo, um campo de estratégias e percepções comuns, mas sim que deu lugar a posições teóricas, políticas e ideológicas diferenciadas. Por outro lado, o debate sobre a aproximação das questões socioambientais à temática do desenvolvimento acabou por constituir-se mais como um discurso de re-acomodação estratégica na gestão do modo de produção capitalista - face às crises retroalimentadas pelo seu ciclo económico - do que uma forma 
efetiva de repensar o problema, o que ocorreu devido a um viés hegemónico e economicista.

Neste contexto, as formas como as bases ideológicas do modelo dominante são introjetadas em países em desenvolvimento, tais como o Brasil e demais países latinoamericanos, são reflexos da consolidação de um discurso dominante sobre as bases teóricas do modelo desenvolvimentista adotado, que só tardiamente voltaria seus olhares para as questões socioambientais.

\section{As políticas de modernização e desenvolvimento do Estado brasileiro e a integração nacional da Amazónia nos modelos de valorização económica}

Do ponto de vista sociológico, podemos compreender como o processo de modernização do Estado brasileiro se traduziu, por um lado, nalguns aspectos de organização das suas estruturas jurídico-administrativas e, por outro, num planeamento político-económico associado a modelos teóricos de desenvolvimento alheios à realidade socialmente diferenciada do país.

As experiências da transição económica de uma economia agrário-exportadora para uma economia industrial em ritmo acelerado levaram a arquitetar, a partir do início do século $\mathrm{XX}$, o discurso dominante sobre a priorização dos fatores económicos como resposta aos problemas sociais. Neste sentido, a modernização pode ser pensada como reflexo dos processos de racionalização do Estado na tentativa de buscar a eficácia do sistema produtivo e da administração pública através de suas instituições políticas.

As mudanças sociais diante da situação socioeconómica do país foram marcadas, inicialmente, por uma intervenção cada vez maior do Estado na economia, principalmente no campo das condições estratégicas do desenvolvimento económico e na consolidação dos ideais de nação. Desta forma, certas teorias do planeamento e da modernização deram suporte às políticas de desenvolvimento que buscavam o crescimento econômico nacional no quadro da emergência e expansão do sistema capitalista. Reflexos destes contextos foram a urbanização e a industrialização brasileira forjadas sobretudo a partir da década de 30, as quais apresentaram fenómenos de transformação política e econômica, representando, segundo Ianni (1999), uma rutura estrutural na sociedade, pela qual passava a crise de transição da sociedade brasileira.

Segundo Brito (2001), a sociedade brasileira encontrava-se numa condição em que a industrialização tardia significou a imposição de um ordenamento produtivo sobre uma estrutura social cercada de elementos sociais tradicionais, que acabaram ativando os elementos organizacionais do capitalismo industrial, intervindo diretamente na economia e redimensionando parcialmente os esquemas políticos tradicionais. Desta forma, acabaria por não poder constituir as bases para um modelo de desenvolvimento mais condicionado à realidade local e suas especificidades regionais, socioeconómicas e ambientais.

28 Estas transformações, ainda segundo o autor, indicam elementos importantes de compreensão dos fenómenos da dinâmica e rearranjos político-institucionais, sobretudo se considerarmos alguns aspetos. Primeiro, não ocorre de forma igual uma racionalização dos processos de modernização da sociedade. 

são absorvidos pela ordem política instituída. Por último, este processo induz ao desenvolvimento de uma economia industrial, tendo como base um núcleo tecnocrático solidificado no interior da instância estatal.

medida em que absorve ou não os elementos pertencentes ao padrão de racionalidade do modelo de Estado nacional desenvolvimentista adotado, a modernização brasileira é marcada por dimensões técnico-burocráticas administrativas de sua estrutura política e económica. Assim, no campo político esta estrutura consolidar-se-ia, propiciando um modelo de desenvolvimento económico incontestável e autonomizando a estrutura burocrática que conduziria às contradições sociais evidenciadas nas décadas posteriores.

31 Esta configuração permitiu que se criassem instrumentos políticos eficazes para acelerar o desenvolvimento da economia industrial, rompendo com a sociedade tradicional sem sequer questionar os modelos e padrões de desenvolvimento aplicados e impostos a sociedades regionalmente diferenciadas, sobretudo no que respeita o uso dos recursos naturais.

Com as transformações sociais decorrentes dos processos político-económicos de refuncionalização da estrutura estatal, surgem novas abordagens de intervenção direta em setores de desenvolvimento do Estado. Neste contexto, podemos chamar a atenção, na esteira de Brito (2001), para o facto de o desenvolvimento económico marcar a separação da instância estatal correspondente à esfera administrativa - a qual passa por uma reformulação na sua estrutura burocrática - e isolar-se da esfera política, demarcando um modelo de desenvolvimento economicista. Neste sentido, para o autor, a modernização e o capitalismo industrial na sociedade brasileira possuem sua fundamentação no autoritarismo que demarca a constituição política do Estado nacional e sua forma excludente para com as questões da sociedade e, mais ainda, sem qualquer preocupação inicial com as questões ambientais, vistas como elemento exterior ao desenvolvimento eminentemente económico. económico aplicados aos países subdesenvolvidos foram assimilados e forjados no âmbito do processo de consolidação dos discursos legitimadores pertinentes a determinados interesses estratégicos. Também é inegável que a particular adoção dos modelos de crescimento económico subjaz às contribuições teóricas engendradas neste processo, sobretudo quando se discute a relevância do pensamento económico brasileiro e de suas matrizes teóricas associadas ao tema do desenvolvimento numa discussão globalmente mais ampla.

O planeamento, como forma de racionalizar as ações do governo a longo prazo, passou a ser o norteador das políticas económicas, gerando no país uma modernização paradoxal ou uma modernização de superfície da estrutura do Estado (Brito, 2001). Isto significa que, no âmbito do projeto racionalizador das instituições políticas, se acreditava em soluções através das medidas de desenvolvimento sob a perspetiva económica; contudo, não se atingiria uma camada mais profunda da realidade brasileira relacionada com as contradições sociais expressas no seu discurso.

Estes impulsos desequilibraram, de maneira desenfreada, uma tendência desenvolvimentista ao processo de modernização do Estado brasileiro. Do ponto de vista contextual às questões ambientais nas regiões afetadas - como na Amazónia brasileira estes fenómenos ocorreram na medida em que elementos de ordem sociopolítica e 
cultural são arrastados para os planos do desenvolvimento económico do capitalismo tardio e periférico consolidado.

A compreensão destes fenómenos, tratando-se de um projeto de modernidade, é crucial para verificarmos como estas diretrizes norteariam os programas de desenvolvimento económico para a Amazónia por meio das políticas de integração, sobretudo considerando, a partir da segunda metade do século XX, as modalidades de governo e Estado em transição no país (do regime ditatorial iniciado na década de sessenta ao democrático-representativo nos anos oitenta).

37 A política de integração regional significou uma tentativa de dar homogeneidade às estruturas socioeconómicas. Neste sentido o papel do Estado brasileiro foi o de impor um processo forçado de modernização acelerada através da crença nos programas de desenvolvimento e valorização económica sem ater-se às consequências socioambientais deste processo, profundamente contextualizadas no modo de vida das sociedades locais.

Particularmente nos estados da Amazónia brasileira esta política de valorização tem início a partir da década de cinquenta, demarcando um processo de homogeneização dos espaços económicos nacionais como consequência da integração, por meio das políticas de desenvolvimento em regiões pouco integradas no espaço económico nacional e global - isto, é claro, a expensas de uma dissolução ou de uma lesão das estruturas regionalmente homogéneas (Altvater, 1989 apud Brito, 2001), sobretudo no que diz respeito aos aspetos socioculturais que demarcam as fronteiras de organização das sociedades locais.

39 Este modo de inserção da Amazónia é marcado pelo naufrágio de sucessivas tentativas de consolidação de políticas de governo sob o interesse estratégico de potenciar o uso dos recursos naturais e a timidez dos processos de industrialização nas capitais amazónicas. A valorização tardia da economia local trouxe, para além de impactos de uma modernização forçada, a procura de melhores ações aplicadas com o objetivo de implantar um sistema com forças para reunir e estabelecer estratégias de aplicação de uma forma centralizada pelo governo federal (Brito, 2001). Estas ações foram pautadas pelo aprofundamento do conceito de valorização, através da discussão sobre o modelo político de desenvolvimento adotado para a região da Amazónia legal. Desta forma, a criação de uma Superintendência do Plano de Valorização da Amazónia (SPVEA) daria uma conotação muito mais económica, adotando-se um modelo de política que recebeu a incumbência de incentivar a valorização económica, em detrimento de uma política de transformações sociais alcançáveis pela sociedade em geral.

As primeiras ações que demarcaram a consolidação do Plano de Valorização Económica da Amazónia foram o estímulo ao desenvolvimento económico de setores considerados potencializáveis, intensificando a produção de matérias-primas, alimentos, financiamento através de créditos capazes de capitalizar a iniciativa privada, estimulando, sobretudo, a criação de colónias agrícolas através do estímulo estratégico da agricultura a partir da ocupação de fronteiras e da introdução de uma mentalidade agrícola na população local, permitindo, assim, "superar hábitos e concepções de trabalho e de organizações advindas do modo de produção local marcado pelos ciclos extrativistas" (SPVEA 1954b: 6 apud Brito, 2001).

41 É interessante observar que a adoção destas estratégias instituía uma dimensão conceitual daquilo que viria a ser chamado de desenvolvimento para a Amazónia, sendo a 
SPVEA, segundo Brito (2001), o órgão que centralizaria e administraria os recursos destinados ao plano de valorização económica da Amazónia.

A partir da década de sessenta, com a decadência das políticas desenvolvimentistas instituídas no pós-guerra, a falta de critérios técnicos para balizar as ações do Estado e a crise política entre a SPVEA e a transição para um governo autoritário-militar eram visivelmente agravadas, criando, desta forma, as condições de falência do plano de valorização económica da Amazónia, sobretudo diante do embate ideológico instituído no período ditatorial.

Ocorre que no ano de 1966, com o anúncio da "Operação Amazónia" instituída pelo Presidente da República Marechal Humberto Castelo, a Superintendência do Plano de Valorização da Amazónia (SPVEA) tornou-se extinta. Neste momento é criada a Superintendência do Desenvolvimento da Amazónia (SUDAM), como outra alternativa ao desenvolvimento de projetos e programas para estimular a economia regional. Esta iniciativa ocorre após a criação de outra instituição, o Banco da Amazónia (BASA), sendo este o agente financeiro das ações governamentais e administrador dos recursos oriundos do governo federal brasileiro e repassados para os estados na Amazónia brasileira através de fundos de investimento privados (Brito, 2001).

No entanto, ao longo das décadas em que se estendeu o plano de atuação política adotado pelo governo militar, tratando-se de um quadro geral, o modelo de desenvolvimento económico manteve, segundo Brum (2009), a característica concentradora porque beneficiou a grande empresa em detrimento da média e pequena, estimulando a fusão de empresas dos setores industriais, comerciais e financeiros e favorecendo desta forma, segundo o autor, a concentração da propriedade da terra, o que viabilizou a grande e a média empresa rural em detrimento da propriedade familiar.

Acredita-se que estas ações, do ponto de vista macroeconómico, possibilitaram, como seu reflexo, a expansão económica nos estados nas regiões mais ricas, deixando as demais regiões, como a Amazónia, para segundo plano. Por conta das superintendências e dos programas de desenvolvimento regional e valorização económica criados, estes tornar-seiam retardatários, privilegiando a lucratividade do capital em detrimento de ganhos do trabalho e medidas paliativas de crescimento económico em regiões periféricas dos grandes centros urbano-industriais produtivistas, gerando desigualdades sociorregionais históricas.

46 As políticas governamentais, na medida em que visavam a consolidação de uma valorização económica de desenvolvimento na região, resultaram em grandes transformações sociais, as quais se traduziram, de facto, em impactos negativos nas populações locais, sobretudo nas comunidades rurais de habitantes indígenas e não indígenas, as quais, até então, dispunham de pouco contacto com a sociedade envolvente. A partir das próximas décadas este processo agravar-se-á cada vez mais, produzindo relações conflituosas pelo acesso aos recursos e bens naturais de consumo, reconfigurando as formas de apropriação dos ambientes e espaços de uso comum.

Do ponto de vista das consequências de um projeto dito modernizador que excluía a sociedade amazónica local, grande parte dos problemas decorrentes dos modelos de desenvolvimento adotados refletia os conflitos socioambientais, geralmente marcados pelo acesso à apropriação, manutenção e exploração dos recursos naturais disponíveis, enquanto fonte de subsistência da vida dos moradores locais e enquanto matéria-prima para as forças do capital na região. Estes aspetos, mais do que nunca, possibilitariam o 
debate entre Estado, desenvolvimento e economia sob uma perspetiva socioambiental mas tardiamente, entre as décadas de oitenta e noventa, com a institucionalização do regime da democracia representativa e o fim da ditadura militar, já que, em termos globais, a questão ambiental estava em discussão há algum tempo e não possuía um espaço político consolidado neste período do país.

\section{A ambientalização do discurso desenvolvimentista}

A partir do final da década de oitenta, tornaram-se mais visíveis as ações políticas que caracterizaram um período de profundas transformações na Amazónia brasileira no que concerne as questões ambientais. A consolidação da ocupação humana na região, a intensificação do desmatamento e a concentração urbana como reflexos do modelo predador de desenvolvimento possibilitaram um amplo debate nacional e internacional sobre o tipo de desenvolvimento que se pretendia para a região e para os recursos naturais de uso comum. A introdução de diversos mecanismos de gestão ambiental possibilitaria um controle integrado dos recursos naturais, fortalecendo o estabelecimento de diretrizes claras sobre administração integrada dos ambientes físicos, através de parcerias com diversas agências e instituições de cooperação nacionais e internacionais.

O surgimento de uma legislação específica para as questões ambientais consolidaria, através da normatização dos órgãos responsáveis, as dimensões representativas do significado atribuído ao uso dos recursos naturais e sua relação com o Estado, a sociedade e o modelo de produção vigente. A construção de um discurso ambiental aparece como elemento norteador das políticas de reestruturação do Estado brasileiro pós-ditadura. A instituição de uma política nacional do meio ambiente trataria de duas questões fundamentais da realidade social contemporânea e que a sociedade brasileira conheceu: as perspetivas de desenvolvimento económico e sua relação com os modelos de gestão dos recursos naturais. A preservação, a melhoria e a recuperação da qualidade ambiental, assegurando as condições de desenvolvimento socioeconómico, aparecem como elementos fundamentais aos interesses da segurança nacional nas políticas ambientais em debate.

Tais elementos compreendem um eixo discursivo sobre o planeamento e gestão dos recursos naturais disponíveis. É claro que estas ações, incorporadas por um modelo central de reordenamento dos bens necessários à sociedade, resultam de objetivos centrais quanto ao modelo de política adotado pelo Estado brasileiro, sobretudo, com a tomada de decisões políticas no cenário internacional frente aos parâmetros de conservação do meio ambiente e a reconfiguração teórica dos modelos e discursos dominantes sobre o desenvolvimento.

51 Neste caso, a formulação de uma política ambiental brasileira incidia, ao mesmo tempo, na preocupação com a exploração e o desgaste dos recursos naturais disponíveis, na medida em que transpareciam os objetivos e a compatibilização do desenvolvimento económico social aliado à preservação e equilíbrio do meio ambiente.

52 É sob este contexto que as transformações socioeconómicas e políticas do Estado brasileiro se articulam num processo histórico global que insere a Amazónia num discurso onde a intensificação de estratégias suscetíveis de superar a assimetria entre o desgaste dos recursos naturais e o modo de produção vigente se tornaria uma 
preocupação global e, sobretudo, do capital, onde se localizam processos mundiais a determinar o impulso ou a imobilização das dinâmicas sociais, políticas e económicas em curso na Amazónia brasileira.

53 Contudo, o plano de ação para modelos de desenvolvimento económico possibilitou a articulação de propostas que assegurassem ainda o discurso da sustentabilidade ambiental e do crescimento económico, ao mesmo tempo que assegurava a reacomodação estratégica do capital (Leff, 2000) como modelo de produção vigente e inserido na região. Esta relação, de facto, não só impõe a região amazónica como objeto de preocupação geopolítica estratégica, como também reflete suas feições históricas e políticas moldadas nos surtos de nacionalização/ internacionalização dos seus lugares, configurando estas estratégias e transformações decorrentes de uma rutura entre as realidades pretéritas e presentes (Silva, 2002).

\section{Considerações finais}

54 Ao interpretarmos as significativas transformações do Estado brasileiro e de suas políticas de planeamento económico por meio da influência dos modelos teóricos desenvolvimentistas, estamos em condições de compreender as mudanças sociais causadas pelos modelos de desenvolvimento adotados a partir da ideia de uma modernização forçada de sua estrutura jurídico-burocrática. 0 desdobramento desta discussão refere-se, sobretudo, à racionalização das esferas de organização económica e política quanto à repercussão das consequências e problemáticas sobre as questões socioambientais, a partir da segunda metade do século XX, e sua articulação com as novas abordagens sobre a questão do desenvolvimento.

Ao passo que o modelo de desenvolvimento adotado marcaria as políticas de valorização económica e a racionalização do aparelho estatal, incorporando um ideal aparentemente progressista, a constituição moderna do Estado brasileiro foi guiada pela lógica do crescimento económico, sobretudo no pós-guerra, com os rearranjos políticos e institucionais advindos da incorporação dos modelos teóricos de desenvolvimento legitimados pelo pensamento económico dominante.

$\mathrm{Na}$ medida em que nas esferas políticas e económicas da sociedade brasileira se consolidavam os elementos condizentes com uma racionalidade (parcial) promovida pelo modelo de economia planeada para o progresso e o desenvolvimento nacional, os aspetos estruturantes da sua conjuntura socioeconómica e política tornaram desconexas a relação entre o Estado, a sociedade civil e as questões resultantes deste processo, assim como a discussão dos modelos de desenvolvimento que incorporariam a questão ambiental.

Os modelos económicos e os programas de desenvolvimento adotados comportaram como principais consequências o subdesenvolvimento periférico e graves transformações socioambientais decorrentes da valorização do capital investido em determinadas regiões do país, como na Amazónia brasileira.

Uma das interpretações sobre a antagónica relação entre as dimensões económicas de orientação lucrativa e as questões ambientais na Amazónia pode ser traduzida e compreendida a partir da contradição no modelo político de desenvolvimento adotado pelo Estado nacional brasileiro, no qual as esferas de ordem política, na medida em que interiorizavam o discurso do desenvolvimento e crescimento económico para além dos custos sociais, acabaram também por externalizar os fatores ambientais. Ou seja, 
deixavam para segundo plano toda a discussão sobre o desgaste dos recursos naturais e sua exploração desenfreada pelo modelo de produção vigente. Tal ocasionou, por exemplo, a sujeição de grupos sociais marginalizados social, económica e geograficamente às transformações oriundas da valorização económica nacional por meio dos grandes projetos desenvolvimentistas levados, em suma, à beira de todas as mudanças decorrentes deste processo.

A criação de hidroelétricas, a exploração sem controlo dos recursos naturais extrativistas e não renováveis, a abertura de estradas e rodovias para a ligação com as grandes cidades, a sobreexploração dos recursos pesqueiros, assim como a ocupação das fronteiras nacionais através da pecuária extensiva e da exploração madeireira e mineral das terras tradicionalmente ocupadas pelas sociedades locais indígenas e não indígenas - todos estes são exemplos claros da sujeição inapropriada à racionalização dos modelos económicos de desenvolvimento instituídos na Amazónia.

Marcado pela incapacidade de acompanhar o ritmo de desenvolvimento planeado, sobretudo, diante das insuficiências e contradições acarretadas pelas forças produtivas e pela acumulação e concentração do capital, o carácter de capitalismo periférico e de economia industrial restringida (Cardoso de Melo, 1982) constituiria uma das bases de compreensão sobre as reais incapacidades quanto aos problemas intrarregionais da sociedade nacional contemporânea. As consequências de uma modernização forçada dos modelos nacionais de desenvolvimento instituído sob a projeção dos grandes programas de valorização económica para a Amazónia, considerando sobretudo a relevância do regime de governo militar-autoritário, impossibilitaram transformações democráticas mais profundas na estrutura social das sociedades amazónicas.

61 Contudo, tratando-se das desigualdades e da exclusão socioeconómicas e políticas instituídas como resultado deste processo, a compreensão sobre as contradições do subdesenvolvimento possibilita reconfigurar atualmente os debates para a construção plural de novas formas de interpretação teóricas e práticas dos modelos de desenvolvimento e de suas experiências sociais em esferas não dominantes do mundo económico e politicamente hegemónico.

62 A circularidade social deste debate na esfera pública comporta um conjunto de contribuições para o pensamento sobre os modelos de desenvolvimento emergentes na contemporaneidade, assim como sobre propostas de racionalização das questões ambientais, como no caso das alternativas do desenvolvimento local/territorial e a discussão de uma participação política da sociedade em geral. Estes aspetos denotam um movimento de ressignificação da questão ambiental, traduzível na apropriação do discurso sobre a temática do meio ambiente e das dinâmicas sociopolíticas instituídas na reconstituição das arenas de debates sobre a questão do desenvolvimento.

BIBLIOGRAFIA

AMIN, Samir (1974), Accumulation on a World Scale. Sussex: The Harvester Press. 
BAILLY, Antoine (1999), "Le developpement local: un choix de societé”, in C. Cavaco (org.), Desenvolvimento rural: desafio e utopia. Lisboa: Centro de Estudos Geográficos da Universidade de Lisboa.

BRITO, Daniel Chaves de (2001), A modernização da superfície: Estado e desenvolvimento na Amazônia. Belém: UFPA/NAEA.

BRUM, Argemiro Jacob (2009), o desenvolvimento econômico brasileiro. Ijuí: Ed. UNIJUí.

CARDOSO DE MELO, João Manuel (1982), O capitalismo tardio. São Paulo: Brasiliense.

CARSON, Rachel (1962), The Silent Spring. Boston: Houghton Miffl in Publisher.

CORREA, Hugo Figueira de Souza e CARDEAL, André Morato Dias (2005), O "Ornitorrinco" e a Dependência no Brasil de Hoje: Atualidade e convergência entre o pensamento de Francisco de Oliveira e a Teoria Marxista da Dependência. Campinas, Sociedade Brasileira de Economia Política.

FORTUNA, Carlos (1987), "Desenvolvimento e Sociologia Histórica: acerca da teoria do sistema mundo capitalista e da semi-periferia", in Sociologia. Problemas e Práticas, 3: 163-193.

FRANK, Andre Gunder (1967), Sociology of Development and Underdevelopment of Sociology. Catalyst,3: 20-73.

FURTADO, Celso (1961), Desenvolvimento e Subdesenvolvimento. Rio de Janeiro: Fundo da Cultura.

FURTADO, Celso (1976), Economic Development of Latin America: a Survey from Colonial Times to the Cuban Revolution. Cambridge: Cambridge University Press.

HABERMAS, Jürgen (1990), o discurso filosófico da modernidade. Lisboa: Publicações Dom Quixote.

HARDIN, Garrett (1968), "The tragedy of the commons", in Science, vol. 162, No. 3859: 1243-1248. Nova Iorque: American Association for the Advancement of Science - AAAS.

HIDALGO CAPITÁN, Antonio Luis (1998), El pensamiento económico sobre desarrollo. De los mercantilistas al PNUD. Huelva: Servicio de Publicaciones de la Universidad de Huelva.

HOSELITZ, Bert F. (1960), The Sociological Aspects of Economics Growth. Chicago: Free Press; Illinois: The Free Press of Glencoe.

IANNI, Octávio (1995/1999), “Dialética da Globalização", in O. Ianni (org.), Teorias da globalização. Rio de Janeiro: Civilização Brasileira.

LEFF, Enrique (2000), Ecologia, Capital e Cultura: Racionalidade ambiental, democracia participativa e desenvolvimento sustentável. Blumenal: Ed. Furb.

MARINI, Rui Mauro (2000), Dialética da dependência. Petrópolis, Rio de Janeiro: Vozes; Buenos Aires: Clacso.

MEADOWS, Donella et al. (1972), The Limits to Growth. Nova Iorque. Universe Books.

PARSONS, Talcott (1964), "Evolutionary Universals of Society”, The American Sociological Review, 29: 339-357.

PARSONS, Talcott [1988(1951)], El sistema social. Madrid: Alianza Editorial.

PREBISCH, Raúl (1963), Dinâmica do Desenvolvimento latino-americano. Rio de Janeiro: Editora Fundo de Cultura.

RAPOZO, Pedro e WITKOSKI, Antonio Carlos (2008), "Novos e velhos dilemas desenvolvimentistas: a transição histórica do discurso de sustentabilidade a partir dos projetos de desenvolvimento econômico sob o plano nacional e internacional", in IV ENANPPAS - Encontro da Associação Nacional de Pesquisa e Pós-Graduação em Ambiente e Sociedade Brasilia. 
REIS, José (1994), “O desenvolvimento local é possível?”, in M. B. Moreira (org.), o desenvolvimento local é possivel?. Lisboa: Sociedade Portuguesa de Estudos Rurais.

ROSTOW, Walt Whitman (1960), Las etapas del crecimiento economico. Buenos Aires: Fondo de cultura economica.

SACHS, Ignacy (1993), Estratégias de transição para o século XXI: Desenvolvimento e meio-ambiente. São Paulo, Studio Nobel: FUNDAP.

SANTOS, Boaventura de Sousa (1985), "O Estado, as relações salariais e o bem-estar social na periferia: o caso português”, Análise Social, vol. 87-88-89: 869-901.

SILVA, Marilene Correa da (2002), Metamorfoses da Amazônia. Manaus: EDUA.

SILVA, Manuel Carlos e CARDOSO, António (2005), “O local face ao global: por uma revisitação crítica dos modelos de desenvolvimento", in M. C. Silva et al., Desenvolvimento e assimetrias sócioespaciais: Perspectivas teóricas e estudos de caso: 28-80. Braga, Núcleo de Estudos em Sociologia/ Universidade do Minho e Inovação à Leitura.

STOHR, W. (1981), "Development from Below: the Bottom-up and the Periphery - Inward Development Paradigm", in W. Stohr e D. Taylor (orgs.), Development from Above or Below?, Nova Iorque: John Wiley \& Sons.

UNEP - United Nations Environment Program (1974), Declaración de Cocoyoc sobre Ambiente y Desarrollo. Cocoyoc, México. United Nations Conference on Trade and Development (UNCTAD).

WALLERSTEIN, Immanuel (1990), o sistema econômico mundial. Porto: Afrontamento.

\section{NOTAS}

1. Como veremos de seguida, sobre o conceito de modernização e seus defensores no quadro da teoria liberal sobre o crescimento, importa ter presentes Rostow (1960) na economia, Parsons (1964, 1988) e Hoselitz (1982) na sociologia. Para uma crítica da abordagem liberal da teoria da modernização, cf. Frank (1971).

2. Particularmente, segundo Silva e Cardoso (2005), nos trabalhos de Rostow (1960) e Hoselitz (1960), os quais diferem teoricamente do conceito de modernização empregado por Habermas (1990) para analisar e explicar os processos de crescimento e desenvolvimento.

3. Sobretudo a partir de Prebisch (1963), mas prosseguida por Furtado (1961, 1996), Frank (1961) e, posteriormente, Wallerstein (1990). Em Portugal, cf. Santos (1985) e Fortuna (1987) e, como síntese dos diversos contributos, Silva e Cardoso (2005).

\section{RESUMOS}

Neste artigo é feita uma reflexão sobre as políticas de modernização e desenvolvimento do Estado brasileiro mediante a análise da sua estrutura jurídico-administrativa no decorrer do século XX. Tal reflexão induz a apresentar uma discussão sobre as teorias do desenvolvimento e respetivos contributos entre as questões ambientais, sem perder de vista as contradições sociais pertinentes aos modelos de desenvolvimento adotados no país e em regiões como a Amazônia brasileira em 
fins de século. Estes aspetos serão apresentados como uma reflexão teórica a partir dos debates sobre as questões ambientais, considerando neste caso a aplicabilidade dos modelos de desenvolvimento na América Latina e a ocorrência de uma espécie de institucionalização da gestão dos recursos naturais.

In this article intend to reflect on the policies of modernization and development of the Brazilian State by the administrative structure in the course of the twentieth century. We present a discussion of theories of development and its theoretical framework between the environmental and social contradictions pertaining to the development models adopted in the country and in regions like the Brazilian Amazon at the end of the century. These aspects are discussed in that our perspective proposes a theoretical reflection from the debates on environmental issues at the heart of the applicability of the models of Latin American Development and the contemporary dynamics of institutionalization of the management of natural resources.

Cet article se penche sur les politiques de modernisation et de développement de la structure de l'administration de l'Etat brésilien au cours du XXe siècle. Nous présentons une discussion des théories du développement et de son cadre théorique, les contradictions entre les facteurs sociaux et environnementaux liés aux modèles de développement adoptés dans le pays et dans des régions comme l'Amazonie brésilienne dans ce siècle. Ces aspects sont discutés dans une perspective théorique des débats sur les questions environnementales au centre de l'applicabilité des modèles de développement en Amérique latine et la dynamique de l'institutionnalisation de la gestion des ressources naturelles.

\section{ÍNDICE}

Keywords: development, environment, State, Brazilian Amazon

Mots-clés: développement, environnement, Etat, Amazonie brésilienne

Palavras-chave: desenvolvimento, meio ambiente, Estado, Amazónia brasileira

\section{AUTORES}

\section{PEDRO RAPOZO}

Centro de Investigação em Ciências Sociais da Universidade do Minho pedro_rapozo@hotmail.com

\section{MANUEL CARLOS SILVA}

Centro de Investigação em Ciências Sociais da Universidade do Minho mcsilva@ics.uminho.pt 